\title{
Analysis the effects of lightweight concrete in the middle layer of multi-layered reinforced concrete structures on the stress-strain state using the finite element method
}

\author{
Elena Korol ${ }^{1}, V u$ Dinh Tho, ${ }^{1, *}$, and Nguyen Huy Hoang ${ }^{1}$ \\ ${ }^{1}$ Moscow State University of Civil Engineering, Yaroslavskoe shosse, 26, Moscow, 129337, Russia
}

\begin{abstract}
The development of methods for the calculating reinforced concrete structures covers a wide range of issues, including the expansion of the application of new innovative materials such as concrete and reinforcement. For usage in the practice of modern construction of multilayer structures made of concrete with different physic-mechanical characteristics, it is compulsory to conduct numerical studies of the stressstrain state of these structures under different types of loading. This article presents an analysis of the influence of the relations between the initial elastic modulus of the outer and middle layers for the stress-strain state and the deflection of three-layer reinforced concrete structures using the finite element method in the program ANSYS Mechanical. Numerical modeling allows comparing the obtained results and building theoretical dependences in a wide range of specified parameters for the construction of sections of multilayer reinforced concrete elements. The obtained scientific results enable to determine rational parameters for modeling various structural solutions of multilayer reinforced concrete structures. This would limit the number of actual test samples, increasing the efficiency of the experiment.
\end{abstract}

\section{Introduction}

At present, multilayer reinforced concrete structures are used in the expansion of fields. One of these is the use of multilayer reinforced concrete structures with a middle layer of low thermal conductivity concrete. Three-layer construction with a heat-insulating layer of light concretes of low average density and strength relate to a special class of reinforced concrete structures. They occupy an intermediate position between conventional reinforced concrete structures and combined composite section with outer layers of reinforced concrete and the middle layer of different types of thermal insulation materials, characterized by low strength and high deformation.

The results of previous studies [1,2] show that cracks do not appear in multilayer reinforced concrete structures until the structure is elastic and the tension in the stretched

\footnotetext{
Corresponding author: vuthoks@gmail.com
} 
zone reaches the ultimate tensile resistance, and the ratio of stresses and strains is subject to Hooke's law. Also, in the above publications of the author $[1,3,4]$, analysis have showed the relationship of the elastic modulus of the middle and outer layers, which influenced the stress and strain of multilayered concrete slab.

However, these estimates are mainly based on the hypotheses of the work of reinforced concrete slabs as beams and the transfer of medium and external concrete materials into a homogeneous material to facilitate the calculation, or the use of empirical methods to calculate and assess the impact of the relationship between the modulus of elasticity of the middle and outer layers on the stress-strain state of multilayer reinforced concrete slabs.

A large variation of the test samples leads to a great amount of time and financial costs.

At present, the development of science and technology has allowed to perform a wide variety of researches using the finite element method and provide results close to full-scale experiments.

\section{Materials and methods of research}

In a three-layered slabs, usually concrete class B12.5 - B30 is used for the outer layers. In the middle layer, lightweight concrete with low thermal conductivity properties is used, with compression resistance of approximately $2.5 \mathrm{MPa}[1,7]$. The thickness of the outer layers is from 40 to $60 \mathrm{~mm}$ to ensure minimum deformation and protection of the reinforcement $[1,5]$.

This article considers three-layer beam with a width of $160 \mathrm{~mm}$, height of $250 \mathrm{~mm}$ and length of $3000 \mathrm{~mm}$. The Outer layers are $40 \mathrm{~mm}$ thick, made of heavy concrete with modulus of elasticity Eext $=12000 \mathrm{Mpa}$, and the average of polystyrene grades $\mathrm{B} 0.35$ to $\mathrm{B} 1.5 \mathrm{MPa}[6]$.

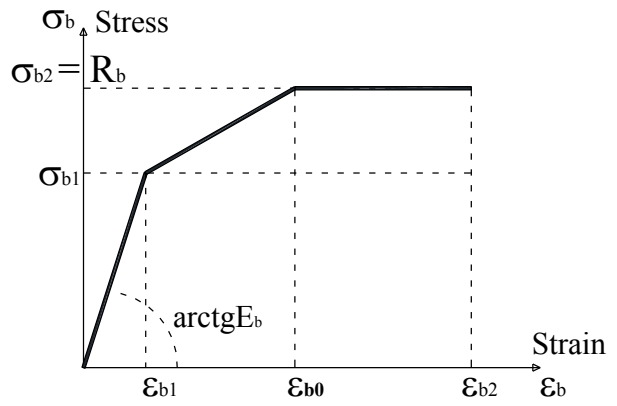

Fig. 1. Diagram of concrete compression.

Where: $\sigma_{b}-$ compressive stresses of concrete;

$\mathrm{R}_{\mathrm{b}}$ - prismatic strength of concrete;

$\varepsilon_{\mathrm{b}}$ - the deformation of concrete;

$\varepsilon_{\mathrm{b} 1} ; \varepsilon_{\mathrm{b} 0} ; \varepsilon_{\mathrm{b} 2}$ - the deformation of concrete corresponding to the stress $\sigma_{\mathrm{b} 1}=0.6 * \mathrm{R}_{\mathrm{b}} ; \sigma_{\mathrm{b} 0}=\mathrm{R}_{\mathrm{b}} ; \sigma_{\mathrm{b} 2}$

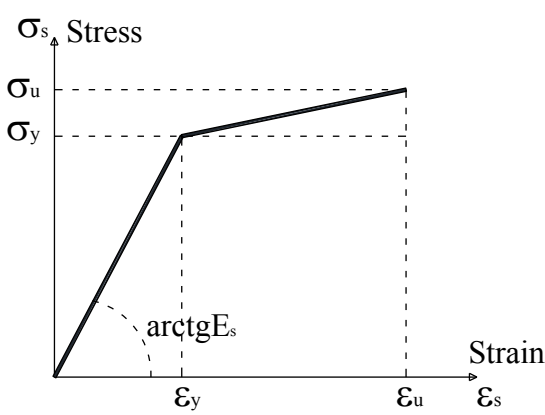

Fig. 2. Stress-strain diagram for reinforcement.

Where: $\sigma_{\mathrm{y}}$ - yield strength of steel; $\sigma_{u}$ - ultimate strength of steel; $\varepsilon_{\mathrm{y}}$ - the deformation of steel when $\sigma_{\mathrm{y}}$; $\varepsilon_{\mathrm{u}}$ - the deformation of steel when $\sigma_{\mathrm{u}}$.

In this type of construction, made of non-uniform materials, under loadings, stress and strain distribution is a rather complex process, so the ratio between the modulus of elasticity of the middle and outer layers haves a strong influence on the stress and strain distribution.

The research methods are based on numerical simulation of stresses and strains of multilayer reinforced concrete elements under the action of various load combinations. The use of modern software systems enables to carry out numerous variable studies, combining a different combination of loads and variability of strength and deformation characteristics 
of materials - structural concrete, low-strength concrete for the middle layer, as well as to compare the results obtained from PC ANSYS with the theoretical results of the calculation. One of the most modern, universal software complexes ANSYS, based on finite element method was used in the article as well as volumetric eight-node finite elements of type SOLID65 and rod elements LINK180 [10].

In SP-63.13330.2012 [6] and in authors' publications [1, 3, 6, 8, 9] the design scheme of distribution of forces and deformations in three-layer reinforced concrete section with monolithic connection of layers is given in Figure 3.
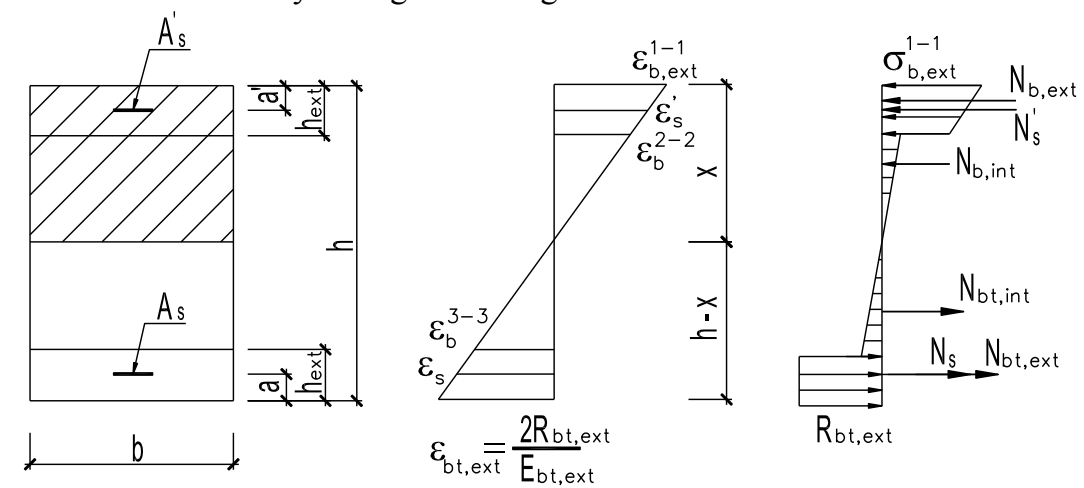

Fig. 3. Caculating schemes of distribution of forces and deformations in three-layer sections at elastic deformations of concrete of the middle layer in the compressed zones.

In the future, the calculation would be conducted for conventional reinforced concrete elements till cracks formation $[1,6]$.

$$
\sigma_{b t} \leq \gamma_{b t} \cdot R_{b t}
$$

$\sigma_{b t}$ - principal tensile stresses;

$\mathrm{R}_{\mathrm{bt}}$ - resistance of concrete to axial tension;

$\gamma_{b t}$ - coefficient of concrete working conditions, taking into account the influence of bi-axial complex stress state "compression-tension" on the strength of concrete.

The deflection of three-layer structures from the bend corresponds to the bending of the beam, and the deflection from the shift is followed with a shift of the filler. In this case, there is a deflection of the cross section with an additional curvature of the outer layers.

The deflection from bending in mid-span of beam specimens to cracking is calculated according to the formula:

$$
f_{M}=\frac{M}{\varphi_{b 1} E_{b} J_{\text {red }}} \rho_{m} l^{2}
$$

The deflection from the transverse forces in any section of the beam element with the coordinate $\mathrm{x}$ is determined by the formula:

$$
f_{Q}=\int \frac{k Q(x)}{G F} d x+C_{Q}
$$

Where: $\mathrm{C}_{\mathrm{Q}}$ - integration constant equal to zero at the hinge support of the beam;

$\mathrm{G}$ - shear modulus of material;

$\mathrm{k}$ - the coefficient that takes into account the shape and dimensions of the cross section, the values of which are determined by the formula:

$$
k=\frac{F}{J^{2}} \int \frac{S^{2}(z)}{b(z)} d z
$$

Where: $\mathrm{F}$ and $\mathrm{J}$ - the area and moment of inertia of the reduced section, respectively; 
$\mathrm{S}$ and $\mathrm{b}$ - the static moment and the width of the cut-off part of the reduced section, respectively.

\section{Results and discussion}

To compare the obtained results of modeling with the real picture of deformations and stresses of three-layer reinforced concrete beam-type samples, the authors will consider the deflection of multilayer concrete slabs of size $160 \times 3000 \times 250 \mathrm{~mm}$ with the parameters presented in table 1 and figure 3. Reinforcement is adopted with a diameter of $8 \mathrm{~mm}$ (A 400) with a step of $15 \mathrm{~cm}$ reinforcement ratio amounted to 0.29 percent. The scheme and nature of the load application is shown in Figure 5. A finite element model with boundary conditions and applied load is shown in Figure 6. Three-layer beam with a width of $160 \mathrm{~mm}$, a height of $250 \mathrm{~mm}$ and a length of $3000 \mathrm{~mm}$ with the parameters presented in table $1[1,6,7,10,12]$. The outer layers are $40 \mathrm{~mm}$ thick, made of heavy concrete with modulus of elasticity Eext $=12000 \mathrm{Mpa}$, and the average of polystyrene concrete grade from $\mathrm{B} 0.35$ to $\mathrm{B} 1.5$.

Table 1. Finite element parameters and characteristics of concrete construction layers.

\begin{tabular}{|l|c|c|c|}
\hline The structure of layers & External (1) & Internal & External (2) \\
\hline The thickness of the layers, $\mathrm{m}$ & 0.04 & 0.170 & 0.04 \\
\hline Prismatic strength of concrete $\mathrm{R}_{\mathrm{b}}, \mathrm{Mpa}$ & 22 & 1.61 & 22 \\
\hline Tensile strength of concrete $\mathrm{R}_{\mathrm{bt}}, \mathrm{Mpa}$ & 1.8 & 0.34 & 1.8 \\
\hline The initial modulus of elasticity E, Mpa & 12000 & 1300 & 12000 \\
\hline Coefficient Poisson $v=0.00189\left|\mathrm{R}_{\mathrm{b}}\right|+0.12$ & 0.161 & 0.122 & 0.161 \\
\hline Shear modulus $\mathrm{G}=\mathrm{E}_{0} /(2(1+v)), \mathrm{Mpa}$ & 5216 & 306 & 5216 \\
\hline The average density of concrete, $\mathrm{kg} / \mathrm{m}^{3}$ & 1800 & 440 & 1800 \\
\hline The modulus of elasticity of reinforcement, Mpa & 210000 & - & 210000 \\
\hline Tensile strength of concrete $\mathrm{R}_{\mathrm{bt}}, \mathrm{Mpa}$ & 1.8 & 0.34 & 1.8 \\
\hline$\phi 8$ - A $400, \sigma_{\mathrm{v}}, \mathrm{Mpa}$ & 400 & & 400 \\
$\sigma_{\mathrm{u}}, \mathrm{Mpa}$ & 440 & & 440 \\
\hline
\end{tabular}
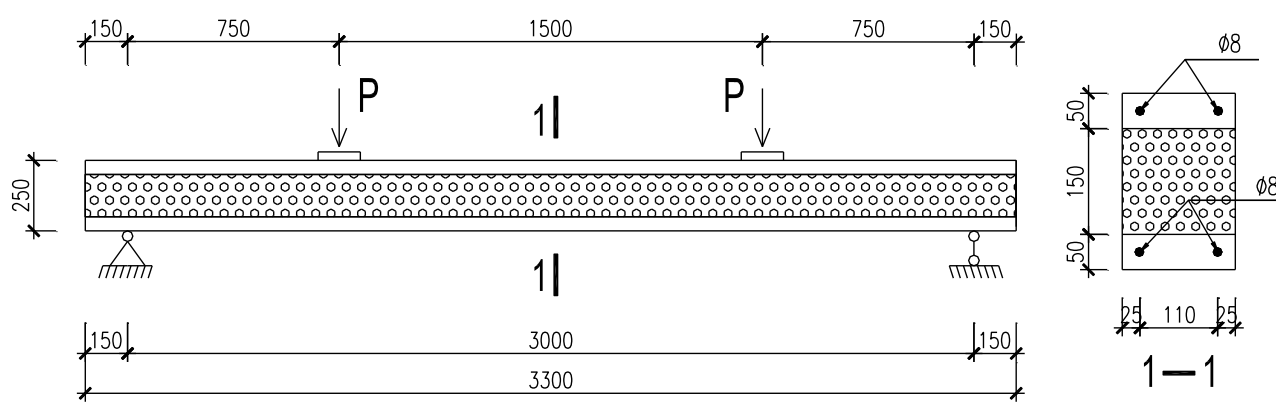

Fig. 4. The parameters of the experimental model. 


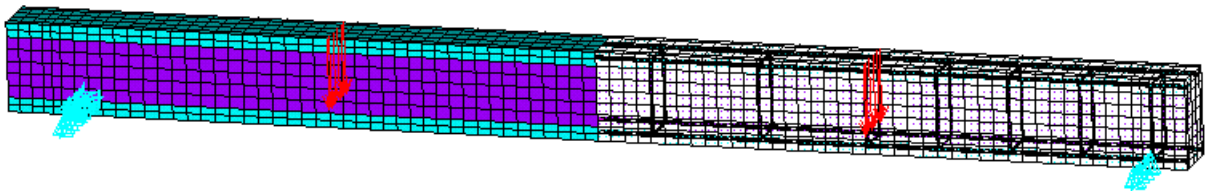

Fig. 5. Finite element model with the display of boundary conditions and loads.

The picture of the initial cracks and the isofield of the stress distribution in the beam during the formation of cracks is shown in Figure 6,7 and 8. When the stress values exceed the limit value of concrete stretching, cracks begin to form in the three-layer beam.

(a)

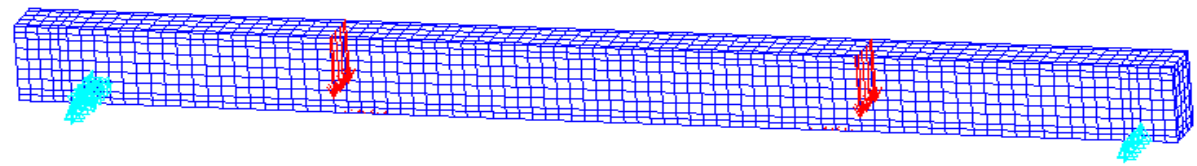

(b)

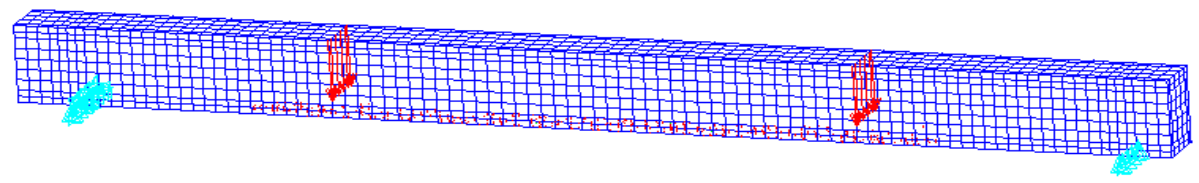

Fig. 6. The distribution of primary cracks: (a) distribution pattern of initial cracks and (b) pattern of cracks in the next stage.

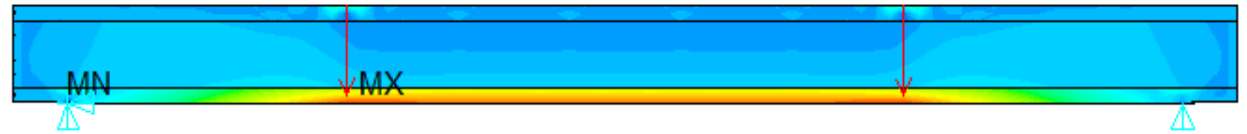

Fig. 7. Stress distribution of the plate in the formation of cracks, MPa.

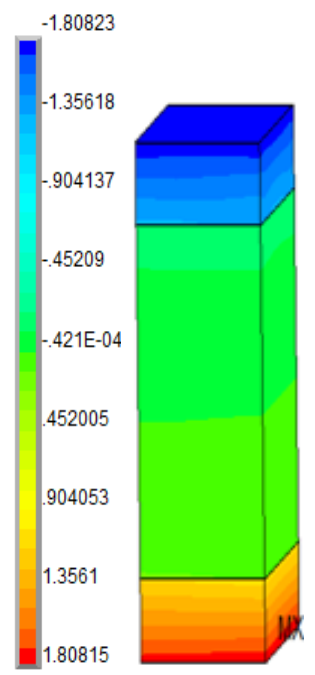

(a)

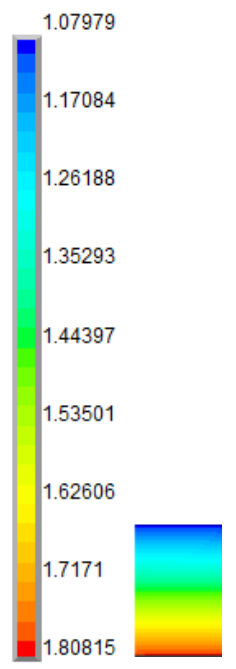

(b)

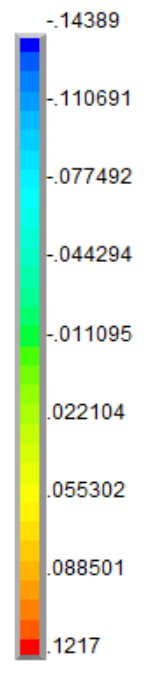

(c)

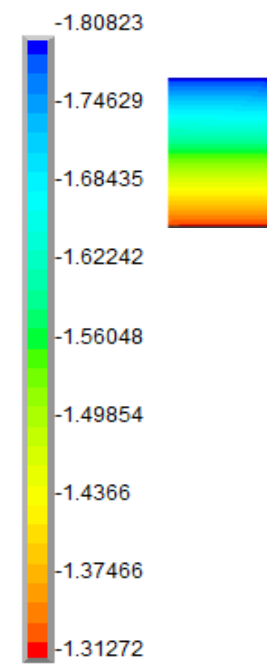

(d)

Fig. 8. Stress distribution in the middle of the span of three-layer beam in the formation of cracks, (MPa): (a) stresses in the middle of the beam span; (b) stresses in the lower layer; (c) stresses in the middle layer and (d) stresses in the top layer.

The first cracks appeared in the middle of the span of a three-layer (at a close position of force), then the cracks diverged throughout the middle of the span of the three-layer beam. This demonstrates that the simulation of a three-layer beam on a software package 
(ANSYS) accurately reflects the actual workflow and the theory of calculation of reinforced concrete beams. Tensile stresses caused by moment and shear .

Comparison of the results with the calculated and experimental results is shown in Figure 9. According to the results from the model in ANSYS, it is showed that at the moment $\mathrm{M}_{\mathrm{crc}}=1.98 \mathrm{kNm}$, cracks begin to form and the value of the moment of crack formation according to the scheme figure $3 \mathrm{M}_{\mathrm{crc}}=2.10 \mathrm{kNm}$ when comparing the calculation results in ANSYS with approximate calculations for SP-63.13330.2012, the difference between the moments of crack formation was $5.8 \%$ for the design scheme in Figure 3.

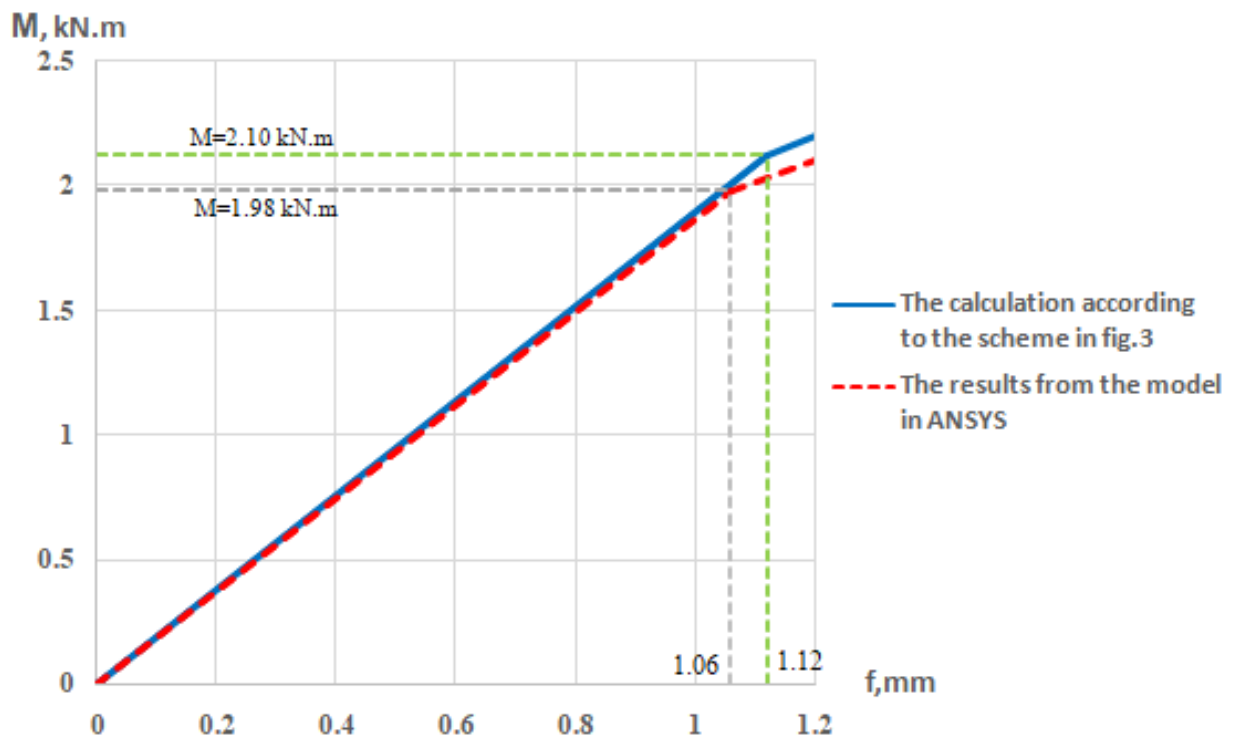

Fig. 9. Dependence of deflections on the moment in the formation of cracks.

On the basis of the above calculations, a comparison of the results of calculations for the modulus of elasticity of the outer layer $E_{\text {ext }}=12000 \mathrm{MPa}, \mathrm{E}_{\text {ext }}=24000 \mathrm{MPa}$ or $E_{\text {ext }}=48000 \mathrm{MPa}$ and the variation of the modulus of elasticity of the middle layer $E_{\text {int }}$ from $60 \mathrm{MPa}$ to $6000 \mathrm{MPa}$, in order to evaluate the effect of changes in the material properties on the change in the initial moment of the beam cracking and deflections in a three-layer reinforced concrete beam. The results of the analysis of moments and deflections in a threelayer reinforced concrete beam are shown in Table 2 and Figure 10 and Figure 11.

Table 2. Moments and deflections of the beam of the initial fracture formation when changing the elastic modules of the middle layer of a three-layer reinforced concrete beam.

\begin{tabular}{|c|c|c|c|c|c|c|}
\hline \multirow{2}{*}{$\begin{array}{c}\mathrm{E}_{\text {int }}, \\
(\mathrm{Mpa})\end{array}$} & \multicolumn{2}{|c|}{$\mathrm{E}_{\mathrm{ext}}=12000 \mathrm{Mpa}$} & \multicolumn{2}{|c|}{$\mathrm{E}_{\mathrm{ext}}=24000 \mathrm{Mpa}$} & \multicolumn{2}{|c|}{$\mathrm{E}_{\mathrm{ext}}=48000 \mathrm{Mpa}$} \\
\hline & $\begin{array}{c}\text { Moment } \\
\mathrm{M}_{\mathrm{crc}}(\mathrm{kN} . \mathrm{m})\end{array}$ & $\begin{array}{c}\text { Deflection } \mathrm{f}, \\
(\mathrm{mm})\end{array}$ & $\begin{array}{c}\text { Moment } \\
\mathrm{M}_{\mathrm{crc}}(\mathrm{kN} . \mathrm{m})\end{array}$ & $\begin{array}{c}\text { Deflection } \mathrm{f}, \\
(\mathrm{mm})\end{array}$ & $\begin{array}{c}\text { Moment } \\
\mathrm{M}_{\mathrm{crc}}(\mathrm{kN} . \mathrm{m})\end{array}$ & $\begin{array}{c}\text { Deflection } \mathrm{f}, \\
(\mathrm{mm})\end{array}$ \\
\hline 60 & 1.21 & 1.66 & 1.23 & 1.39 & 1.25 & 1.18 \\
\hline 120 & 1.37 & 1.55 & 1.4 & 1.26 & 1.42 & 1.02 \\
\hline 300 & 1.56 & 1.33 & 1.61 & 1.02 & 1.63 & 0.61 \\
\hline 600 & 1.83 & 1.15 & 1.89 & 0.81 & 1.94 & 0.42 \\
\hline 1200 & 1.98 & 1.06 & 2.05 & 0.7 & 2.1 & 0.35 \\
\hline 3000 & 2.14 & 1.01 & 2.19 & 0.65 & 2.24 & 0.32 \\
\hline 6000 & 2.19 & 0.97 & 2.24 & 0.61 & 2.29 & 0.3 \\
\hline
\end{tabular}


From the results of the model three-layer reinforced concrete beams showed that the initial modulus of elasticity of the outer layer $E_{\text {ext }}=12000 \mathrm{Mpa}$, and the changes of the initial modulus of elasticity of the middle layer of three-layer reinforced concrete beam in the range from $60 \mathrm{MPa}$ to $1200 \mathrm{MPa}$, the moment at which it begins to crack, varies greatly (from $100 \%$ to $163 \%$ ); the initial modulus of elasticity of the outer layer $\mathrm{E}_{\mathrm{ext}}=24000 \mathrm{Mpa}$ changes (from $100 \%$ to $166 \%$ ); and the initial modulus of elasticity of the outer layer $\mathrm{E}_{\mathrm{ext}}=48000 \mathrm{Mpa}$ changes (from $100 \%$ to $168 \%$ ).

When the initial modulus of elasticity of the outer layer $\mathrm{E}_{\text {ext }}=12000 \mathrm{Mpa}$, and the changes of the initial modulus of elasticity of the middle layer of three-layer reinforced concrete beam in the range from $1200 \mathrm{MPa}$ to $6000 \mathrm{MPa}$, the moment at which it begins to crack, varies greatly (from $100 \%$ to $110.6 \%$ ); the initial modulus of elasticity of the outer layer $\mathrm{E}_{\mathrm{ext}}=24000 \mathrm{Mpa}$, changes (from $100 \%$ to $109.3 \%$ ); and the initial modulus of elasticity of the outer layer $\mathrm{E}_{\mathrm{ext}}=48000 \mathrm{Mpa}$, changes (from $100 \%$ to $109 \%$ ).

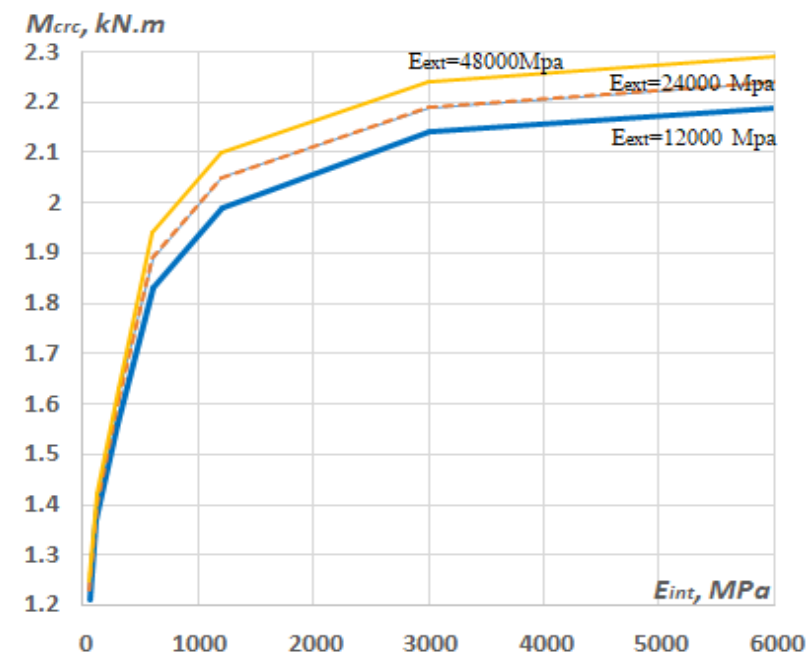

Fig. 10. Graph of fracture formed when changing the modulus of elasticity of the middle layer $\mathrm{E}_{\text {int }}$ from $60 \mathrm{Mpa}$ to $6000 \mathrm{Mpa}$.

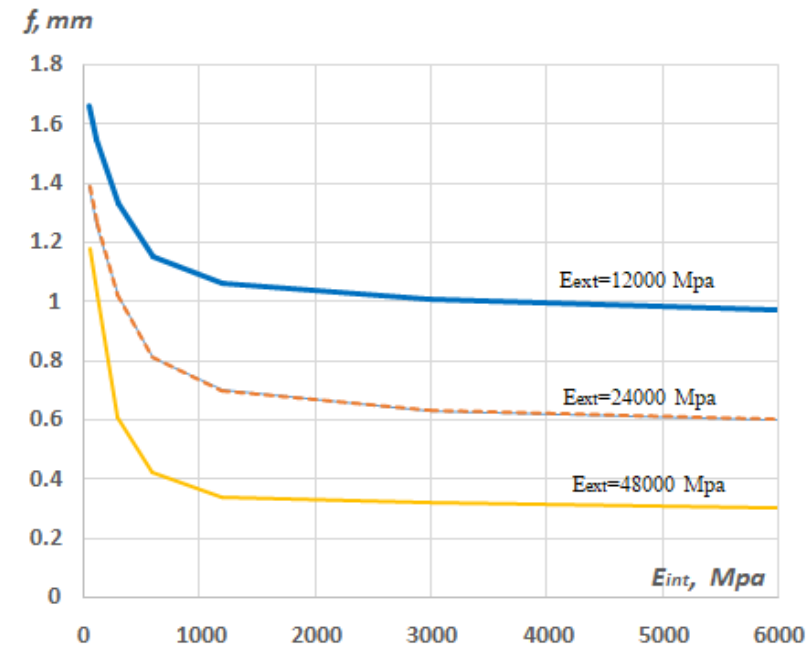

Fig. 11. The graph of the deflection formed by the crack when the modulus of elasticity of the middle layer $\mathrm{E}_{\text {int }}$ changes from $60 \mathrm{Mpa}$ to $6000 \mathrm{MPa}$. 
The results of the model three-layer reinforced concrete beams showed that the initial modulus of elasticity of the outer layer $E_{\text {ext }}=12000 \mathrm{Mpa}$, and the changes of the initial modulus of elasticity of the middle layer of three-layer reinforced concrete beam in the range from $60 \mathrm{MPa}$ to $1200 \mathrm{MPa}$, the deflection at which it begins to crack, highly variable (from $100 \%$ to $157 \%$ ); the initial modulus of elasticity of the outer layer $\mathrm{E}_{\text {ext }}=24000 \mathrm{Mpa}$ changes (from $100 \%$ to $198 \%$ ); and the initial modulus of elasticity of the outer layer $\mathrm{E}_{\text {ext }}=48000$ Mpa changes (from $100 \%$ to $337 \%$ ).

At the initial modulus of elasticity of the outer layer $\mathrm{E}_{\text {ext }}=12000 \mathrm{Mpa}$, and changes in the initial modulus of elasticity of the middle layer of a three-layer reinforced concrete beam in the range from $1200 \mathrm{MPa}$ to $6000 \mathrm{MPa}$, the deflection, in which the formation of cracks, varies greatly (from $100 \%$ to $109.2 \%$ ); at the initial modulus of elasticity of the outer layer $\mathrm{E}_{\mathrm{ext}}=24000 \mathrm{Mpa}$, it changes (from $100 \%$ to $114.8 \%$ ); and at the initial modulus of elasticity of the outer layer $\mathrm{E}_{\mathrm{ext}}=48000 \mathrm{Mpa}$, it changes (100\% to $\left.116.7 \%\right)$.

\section{Conclusion}

1. The final analysis shows similar results obtained by numerical methods using the ANSYS PC, compared to experimental studies and theoretical calculations. The results of analysis of moments and deflections of multilayer reinforced concrete beams of ANSYS are usually lower compared to the result of moments and deflections when calculated according to the theory scheme ( from 3 to $7 \%$ ).

2. When changing the modulus of elasticity of the middle layer of three-layer reinforced concrete slab in the range from $60 \mathrm{MPa}$ to $1200 \mathrm{MPa}$, a modulus of elasticity of the outer layer $\mathrm{E}_{\text {ext }}=12000 \mathrm{Mpa} ; \mathrm{E}_{\mathrm{ext}}=24000 \mathrm{Mpa}$ or $\mathrm{E}_{\mathrm{ext}}=48000 \mathrm{Mpa}$, moments and deflections of cracking varies greatly. The greater the modulus of elasticity of the outer layer varies greatly, the greater the change in the value of the moment and the deflection of the formation of cracks.

3. When changing the elastic modulus of the middle layer of a three-layer reinforced concrete slab in the range from $1200 \mathrm{MPa}$ to $6000 \mathrm{MPa}$, the modulus of elasticity of the outer layer $\mathrm{E}_{\mathrm{ext}}=12000 \mathrm{Mpa}, \mathrm{E}_{\mathrm{ext}}=24000 \mathrm{Mpa}$ or $\mathrm{E}_{\mathrm{ext}}=48000 \mathrm{Mpa}$, the moments of formation of cracksdo not change much (100\% to $110.6 \%)$ and crack formation deflections, change (100\% to $116.7 \%)$.

This work was financially supported by Ministry of Education and Science of the Russian Federation (\#NSh-3492.2018.8).

\section{References}

1. E.A. Korol, Three-layer enclosing reinforced concrete structures made of lightweight concrete and features of their calculation (Asv, Moc, 2001)

2. I. Bujnak, E.A. Korol, V.E. Latushkin, Communication, 1, 101 ( 2012)

3. E.A. Korol, Y.A. Kharkin, Vestnik MSSU, 3, 156-163 (2010)

4. Е.А. Король, Е.M. Pugach, A. Kharkinu, Vestnik MSSU, 3, 67 (2014)

5. E.A. Korol, NSUACE, 5, 11 (2004)

6. SP 63-13330-2012, Concrete and reinforced concrete structures (Standard, Rus, 2012)

7. GOST R 51263-2012, Polystyrene concrete. Technical conditions (Standard, Rus, 2012)

8. E.A. Korol, LOAF, 2, 5 (2000)

9. J. Bujnak, E.A. Korol, V.E. Latushkin, Communication, 1, 101 (2012) 
10. K. Phuvoravan, D.E. Sotelino, ABSE, 131, 643 (2005)

11. K. Willam, T. Tanabe, Farmington hills, Ameri, SP, 205 (2001)

12. S.N. Bogatova, A.D. Bogatov, Industrial and civil construction, 4, 52 (2011) 